\title{
Factors Associated with Treatment Outcome of Patients with Pulmonary Tuberculosis in the Philippines, 2015 to 2016
}

\author{
Ian Oliver D. Macatangay, ${ }^{1}$ Sophia Anne S.P. Liao, ${ }^{1}$ Joshua Jason A. Dadural, ${ }^{1}$ Fatima Joy S. Gagui, ${ }^{1}$ \\ Angelica Joy A. Galas, ${ }^{1}$ Raymond Dorutheo Francis A. San Antonio ${ }^{1}$ and Paul Adrian V. Pinlac ${ }^{2}$ \\ ${ }^{1}$ College of Public Health, University of the Philippines Manila \\ ${ }^{2}$ Department of Epidemiology and Biostatistics, College of Public Health, University of the Philippines Manila
}

\begin{abstract}
Objective. The study aims to determine the factors associated with unsuccessful treatment outcome among patients who have undergone tuberculosis treatment.

Methods. An analytic cross-sectional study was employed through secondary data analysis of administrative data collected by the National Tuberculosis Control Program from October 2015 to September 2016. Using multiple logistic regression analysis, factors associated with unsuccessful treatment outcome were determined.
\end{abstract}

Results. Multiple logistic regression analysis revealed that belonging to age groups 25 to 34 (aOR=0.73; $95 \% \mathrm{Cl}$ 0.54-0.99) or 35 to $44(\mathrm{aOR}=0.75 ; 95 \% \mathrm{Cl} 0.56-0.99)$, being male $(\mathrm{aOR}=1.30 ; 95 \% \mathrm{Cl} 1.03-1.64)$, doing crafts and related trades work $(\mathrm{aOR}=0.66 ; 95 \% \mathrm{Cl} 0.46-0.94)$, living in either a 4th class city $(\mathrm{aOR}=0.46 ; 95 \% \mathrm{Cl}$ $0.26-0.82)$, 1st class municipality $(\mathrm{aOR}=0.75 ; 95 \% \mathrm{Cl} 0.57-0.98)$, 4th class municipality $(\mathrm{aOR}=0.59 ; 95 \% \mathrm{Cl}$ $0.38-0.93)$, having a positive sputum smear result (aOR=1.60;95\% Cl 1.29-2.00), having rifampicin-resistant/ multidrug-resistant tuberculosis (aOR=9.32; 95\% Cl 7.28-11.93), being a treatment after lost to follow-up case $(\mathrm{aOR}=1.84 ; 95 \% \mathrm{Cl} 1.37-2.47)$ or a case with previously unknown treatment outcome $(\mathrm{aOR}=1.42 ; 95 \% \mathrm{Cl} 1.00-2.01)$ were significant correlates of unsuccessful treatment outcome.

Conclusion. The study found that age, sex, occupation, residence, sputum smear results, drug resistance, and history of previous treatment were associated with unsuccessful treatment outcome.

Key Words: tuberculosis, pulmonary, treatment outcome, regression analysis, Philippines

\section{INTRODUCTION}

Paper presented at the $9^{\text {th }}$ International Academic Consortium for Sustainable Cities Conference, September 11-12, 2018, AG New World Manila Bay Hotel Malate, Manila, Philippines.

Corresponding author: lan Oliver D. Macatangay College of Public Health

University of the Philippines Manila

625 Pedro Gil St., Ermita, Manila 1000, Philippines

Email: idmacatangay@up.edu.ph
Tuberculosis (TB) is still one of the leading causes of death worldwide. The Western Pacific Region alone had 1.8 million reported cases, 32\% of which came from the Philippines. ${ }^{1}$ Despite the implementation of various strategies and control measures, the Philippines is one of 20 countries with the highest TB burden globally, and is also 4th among the largest number of estimated incident cases in the world. ${ }^{2}$ The National TB Prevalence Survey (NTPS) of 2016 showed an increasing prevalence of both cultureconfirmed $\mathrm{TB}$ cases and rifampicin-resistant/multidrugresistant TB (RR-/MDR-TB) cases in the country. ${ }^{1-3}$

Although there is an increase in Treatment Success Rate (TSR), tuberculosis remains as one of the top killers in the country. Even if the Philippines reached the Millennium Development Goals (MDG) target of TSR >90\%, some 
regions were found to have differences in TSR based on the 2014 NSP TB Cohort, namely: Regions IV-B, Autonomous Region of Muslim Mindanao (ARMM), and the National Capital Region (NCR). ${ }^{4}$ Moreover, TSR among drugresistant (DR-TB) cases did not reach the 2016 target of $75 \%$ (i.e., only reaching 49\%), and is far from the updated $85 \%$ target established in PhilSTEP1. ${ }^{3}$

According to the Global Tuberculosis Report 2017, it is essential to analyze the treatment outcome as it would be helpful in understanding the epidemic of the disease and in monitoring the progress of the control programs implemented by the country so that any perceived beneficial adjustments in the national and local strategies are done. ${ }^{2}$ Although various studies worldwide have assessed the factors that may be associated with treatment outcome, significant results vary across countries. In the Philippines, only a few studies have looked into the risk factors associated with specific outcomes such as death and lost to follow-up., ${ }^{5,6}$ Hence, a study done in a Philippine setting might offer a unique and local perspective of the factors considered, especially to those that appear to be inconclusive in many studies globally (i.e., occupation, residence type, drug resistance, and hypertension). Given this concern, the study aims to determine the factors associated with unsuccessful treatment outcome among patients who have undergone tuberculosis treatment in the Philippines.

\section{MATERIALS AND METHODS}

\section{Study Design and Period}

The National Tuberculosis Control Program (NTP) of the Department of Health (DOH) is responsible for collecting quarterly reports submitted by Directly Observed Treatment Short Course (DOTS) facilities nationwide. An analytic cross-sectional study was conducted through a secondary data analysis of administrative data collected by the program from October 2015 to September 2016, which is the most recent one-year data available by the time the study was conducted. The most recent data available was used to provide a more accurate reflection of the characteristics of the current patient population. This was limited to a oneyear time span with the assumption that the characteristics of the previous populations (i.e. in the last 5 years at most) in terms of factors related to treatment outcome were not expected to differ from the current population.

\section{Target Population}

The target population consisted of all pulmonary tuberculosis (PTB) patients in the Philippines. The study involved the total enumeration all PTB patients registered in the NTP of the DOH from the chosen time span.

\section{Study Variables}

The dependent variable is the treatment outcome which refers to the status of the patient after undergoing treatment.
It was identified through the treatment outcome column, as indicated in the NTP database. It was classified into two main categories namely successful and unsuccessful outcome, based on the NTP Manual of Procedures. ${ }^{7}$ Successful outcome was further classified into (1) "cured" which refers to a patient with bacteriologically-confirmed $\mathrm{TB}$ at the beginning of treatment who was smear- or culture- negative in the last month of treatment and on at least one previous occasion in the continuation phase and (2) "treatment completed" which refers to a patient who completed treatment without evidence of failure but with no record to show that sputum smear or culture results in the last month of treatment and on at least one previous occasion were negative, either because tests were not done or the results are unavailable. On the other hand, unsuccessful treatment outcome includes (1) "lost to follow-up" which pertains to a patient whose treatment was interrupted for two consecutive months or more, (2) "treatment failed" which refers to a patient whose sputum smear or culture is positive at 5 months or later during treatment OR a clinically-diagnosed patient (child or extra- pulmonary TB) for whom sputum examination cannot be done and who does not show clinical improvement anytime during treatment, and (3) "died" which pertains to a patient who dies for any reason during the course of treatment. This study took particular interest in the occurrence of unsuccessful treatment outcome.

The independent variables, which were identified from existing literature and selected based on its availability in the given NTP database, included sociodemographic, TB-related, and health history factors. ${ }^{5,6,8-31}$ For this study, the occupation was classified based on the Philippine Standard Occupational Classifications (PSOC) while residence the type was classified based on the Philippine Standard Geographical Code (PSGC), both from the Philippine Statistics Authority (PSA). TB-related factors included sputum smear results, Xpert MTB/Rif results, drug resistance, and history of previous treatment. The definition and categories for the said variables were based on the NTP Manual of Procedures. ${ }^{7}$ Lastly, health history factors included diabetes, hypertension, alcohol consumption, and smoking consumption.

\section{Inclusion and Exclusion Criteria}

The study included patients registered in the NTP from October 2015 to September 2016 with known treatment outcome, as well as those who were 18 to 99 years old. Excluded from the study were those who have undergone more than two treatment courses. A total of 422,551 anonymized patient records were obtained from the NTP database. Applying all the criteria resulted in the inclusion of 338,376 patient records for descriptive analysis. However, only 3,701 patient records were included in the logistic regression analysis since those with missing data, especially the four health history variables (i.e., diabetes, hypertension, alcohol consumption, and smoking status), 
were dropped from this analysis. In addition, patient records with the following categories were also excluded: unclassified residence and/or occupation, not done Xpert $\mathrm{MTB} / \mathrm{RIF}$ and/or direct sputum smear microscopy, and/or invalid/no result/error for Xpert MTB/RIF. Given that, the resulting number of patient records for the logistic regression analysis exceeded the minimum sample size of 3,037.

\section{Data Processing and Analysis}

A coding manual was prepared for data re-coding of all information obtained from the NTP. The data was processed in Microsoft Excel 2013 and was screened for inconsistencies and incompleteness prior to analysis, which involved descriptive and analytical methods. Odds ratios (ORs) were determined with a $5 \%$ level of significance using simple and multiple logistic regression analyses through STATA version 12.

\section{Ethical Considerations}

This research was subjected to ethics review by the University of the Philippines Manila Research Ethics Board (UPMREB) and has been endorsed favorably by the said committee.

\section{RESULTS}

\section{Characteristics of PTB Patients Registered in the NTP}

The mean age of the patients was 46.02 years old $( \pm 17.04$ years) and $33.98 \%$ of them were 55 to 99 years old. Most of the patients in the study were males (66.44\%). Their occupations were varied but the majority of those with jobs were skilled agricultural, forestry, and fishery workers (20.04\%). Majority resided in 1st Class areas wherein $27.09 \%$ live in 1st Class Cities while $27.85 \%$ live in 1 st Class Municipalities. In addition, $14.74 \%$ came from Region IV-A, $13.96 \%$ from NCR, and $10.33 \%$ from Region III.

Among those who had results for direct sputum smear microscopy $(n=317,053)$, most had negative results (60.8\%). It was identified in the data given by the NTP that majority of the patients (66.14\%) did not undergo the Xpert MTB/RIF assay. MTB was detected in $17.37 \%$ of the patients who underwent the assay, although their results on Rifampicin resistance varied. On the other hand, 98.97\% of the patients were drug-susceptible while only $1.01 \%$ were RR-/MDR-TB. Only 10 out of the 338,376 patients had extensively-drug resistant TB. It must be noted that drug resistance was based on the DR- TB Bacteriologic Status, as indicated in the database. With regard to their history of previous TB treatment, majority of the patients were new cases (86.42\%) while approximately 14\% had been previously treated (i.e., relapse, treatment after failure, and treatment after lost to follow-up).

Out of the 71,589 patients with data on diabetes mellitus, more than $99.99 \%$ were reported to have the disease. Similarly, $99.85 \%$ of the patients with data on hypertension $(n=17,885)$ were reported to have the said disease. More than half (61.97\%) of the patients with relevant data $(\mathrm{n}=32,041)$ were reported to consume alcohol. Likewise, $60.26 \%$ of the patients with relevant data $(\mathrm{n}=43,264)$ had a history of smoking.

Table 1 describes the distribution of patients with respect to their treatment outcome. Majority of the patients completed their treatment and almost one-third were said to be cured. This indicates a treatment success rate (TSR) of $91.27 \%$ (95\%CI 91.18- 91.37) for all PTB patients registered in the NTP from October 2015 to September 2016. Among the unsuccessful outcomes, patients who were lost to follow-up were more frequent (5.07\%) compared to the other categories.

Table 1. Treatment Outcome of PTB Patients Registered in the NTP, October 2015 - September $2016(n=338,376)$

Treatment Outcome Frequency Percent (\%) $95 \% \mathrm{Cl}$

$\begin{array}{llll}\text { Cured } & 106,408 & 31.45 & 31.29-31.60\end{array}$

Treatment Completed $\quad 202,443 \quad 59.83 \quad 59.66-59.99$

Lost to Follow-up $\quad 17,162 \quad 5.07 \quad 5.00-5.15$

$\begin{array}{llll}\text { Treatment Failed } & 1,865 & 0.55 & 0.53-0.57\end{array}$

\begin{tabular}{llll} 
Died & 10,498 & 3.10 & $3.04-3.16$ \\
\hline
\end{tabular}

a Definitions of the categories are stated in "Materials and Methods: Study Variables"

Among all the patients who were drug susceptible, majority of them had a successful treatment outcome. On the other hand, $60.30 \%$ (95\%CI 58.65-61.93) of patients with RR-/MDR-TB had an unsuccessful treatment outcome. For those with XDR-TB, 8 had an unsuccessful treatment outcome. (Table 2)

\section{Factors Associated with Treatment Outcome of PTB Patients (Table 3)}

Among the predetermined factors analyzed, only age was not found to be associated with treatment outcome, without controlling for the other variables. The simple logistic regression analysis showed that being male increases the odds of having unsuccessful treatment outcome by $40 \% \quad(\mathrm{OR}=1.40 ; 95 \% \mathrm{CI}$ 1.14-1.72). Being professionals $(\mathrm{OR}=0.34 ; 95 \% \mathrm{CI} \quad 0.12-0.95)$, skilled agricultural, forestry, and fishery workers $(\mathrm{OR}=0.66 ; 95 \% \mathrm{CI} \quad 0.49-0.88)$, and craft and related trades workers $(\mathrm{OR}=0.70 ; 95 \% \mathrm{CI} 0.50$ 0.97) were less likely of having unsuccessful treatment outcome, similarly to patients who resided in a 4th Class City $(\mathrm{OR}=0.32$; 95\%CI 0.18-0.56), 1st Class Municipality (OR=0.72; 95\%CI 0.56-0.95), 2nd Class Municipality $(\mathrm{OR}=0.55 ; 95 \% \mathrm{CI}$ 0.37- 0.81), 3rd Class City $(\mathrm{OR}=0.64$; $95 \% \mathrm{CI} 0.41-0.99)$, or 4 th Class Municipality $(\mathrm{OR}=0.42$; 95\% CI 0.27-0.64).

The analysis also revealed that the odds of having an unsuccessful treatment outcome of patients with positive sputum smear results were nearly three times higher than 
Table 2. Treatment Outcome and Drug Resistance of PTB Patients in the Philippines, October 2015 - September 2016 ( $\mathrm{n}=338,376$ )

\begin{tabular}{|c|c|c|c|c|c|c|}
\hline Drug Resistance & $\mathbf{n}$ & $\begin{array}{c}\text { Cured } \\
n(\%)^{a} 95 \% \mathrm{Cl}\end{array}$ & $\begin{array}{c}\text { Treatment } \\
\text { Completed } \\
\text { n (\%) } 95 \% \mathrm{Cl}\end{array}$ & $\begin{array}{c}\text { Lost to Follow-Up } \\
\text { n (\%) } 95 \% \mathrm{Cl}\end{array}$ & $\begin{array}{c}\text { Treatment Failed } \\
\mathrm{n}(\%)^{\mathrm{a}} 95 \% \mathrm{Cl}\end{array}$ & $\begin{array}{c}\text { Died } \\
\text { n (\%) }{ }^{\mathrm{a}} 95 \% \mathrm{Cl}\end{array}$ \\
\hline Drug Susceptible ${ }^{b}$ & 334,880 & $\begin{array}{c}105,444(31.49) \\
(31.33-31.64)\end{array}$ & $\begin{array}{c}202,001(60.32) \\
(60.15-60.49)\end{array}$ & $\begin{array}{c}15,643(4.67) \\
(4.60-4.74)\end{array}$ & $\begin{array}{l}1,812(0.54) \\
(0.52-0.57)\end{array}$ & $\begin{array}{l}9,980(2.98) \\
(2.92-3.04)\end{array}$ \\
\hline RR-/MDR-TBc & 3,423 & $\begin{array}{c}958(27.99) \\
(26.51-29.52) \\
\end{array}$ & $\begin{array}{c}401(11.71) \\
(10.68-12.84)\end{array}$ & $\begin{array}{c}1,500(43.82) \\
(42.17-45.49) \\
\end{array}$ & $\begin{array}{c}52(1.52) \\
(1.16-1.99) \\
\end{array}$ & $\begin{array}{c}512(14.96) \\
(13.80-16.19) \\
\end{array}$ \\
\hline XDR-TB ${ }^{d}$ & 10 & $\begin{array}{c}1(10.00) \\
(0.89-57.84) \\
\end{array}$ & $\begin{array}{c}1(10.00) \\
(0.89-57.84) \\
\end{array}$ & $\begin{array}{c}4(40.00) \\
(12.51-75.65) \\
\end{array}$ & $0(0.00)$ & $\begin{array}{c}4(40.00) \\
(12.51-75.65) \\
\end{array}$ \\
\hline Unspecified Resistance ${ }^{\mathrm{e}}$ & 63 & $\begin{array}{c}5(7.94) \\
(3.26-18.07) \\
\end{array}$ & $\begin{array}{c}40(63.49) \\
(50.65-74.66) \\
\end{array}$ & $\begin{array}{c}15(23.81) \\
(14.69-36.19)\end{array}$ & $\begin{array}{c}1(1.59) \\
(0.21-10.95) \\
\end{array}$ & $\begin{array}{c}2(3.17) \\
(0.76-12.24) \\
\end{array}$ \\
\hline
\end{tabular}

a Row percentage

$b$ Drug-Susceptible refers to non-resistance to any first-line anti-TB drug as indicated in the database.

c RR-/MDR-TB (Rifampicin/Multidrug Resistant TB) refers to any resistance to Rifampicin, with the exception of those identified as XDR- TB.

$d$ XDR-TB (Extensively Drug-Resistant TB) refers to resistance to any fluoroquinolone and to at least one of three second-line injectable drugs (Capreomycin, Kanamycin, and Amikacin), in addition to multidrug resistance.

$e$ Unspecified Resistance would refer to the resistance that cannot be classified under the previously stated categories

Table 3. Significant Correlates of Unsuccessful Treatment Outcome of PTB Patients in the Philippines, October 2015 - September $2016(n=3,701)$

\begin{tabular}{|c|c|c|c|c|c|c|}
\hline Variable & $\mathbf{n}$ & Unsuccessful TO n (\%) & Unadjusted OR (95\% Cl) & p-value & Adjusted OR (95\% Cl) & p-value \\
\hline \multicolumn{7}{|l|}{ Age } \\
\hline $25-34$ years old & 542 & $77(14.21)$ & $0.86(0.55-1.33)$ & 0.502 & $0.73(0.54-0.99)$ & 0.044 \\
\hline $35-44$ years old & 606 & $86(14.19)$ & $0.87(0.56-1.34)$ & 0.525 & $0.75(0.56-0.99)$ & 0.046 \\
\hline \multicolumn{7}{|l|}{ Sex } \\
\hline Male & 2,508 & $388(15.47)$ & $1.36(1.06-1.75)$ & 0.016 & $1.3(1.03-1.64)$ & 0.026 \\
\hline \multicolumn{7}{|l|}{ Occupation } \\
\hline Craft and related trades workers & 396 & $48(12.12)$ & $0.56(0.38-0.82)$ & 0.003 & $0.66(0.46-0.94)$ & 0.02 \\
\hline \multicolumn{7}{|l|}{ Residence Type } \\
\hline 4th Class City & 218 & $14(6.42)$ & $0.32(0.18-0.56)$ & 0.003 & $0.46(0.26-0.82)$ & 0.008 \\
\hline 1st Class Municipality & 650 & $88(13.54)$ & $0.72(0.56-0.95)$ & 0.008 & $0.75(0.57-0.98)$ & 0.037 \\
\hline 4th Class Municipality & 303 & $25(8.25)$ & $0.42(0.27-0.64)$ & 0.009 & $0.59(0.38-0.93)$ & 0.023 \\
\hline \multicolumn{7}{|l|}{ Sputum Smear Results } \\
\hline Positive & 2,698 & $280(10.38)$ & $2.85(2.36-3.44)$ & $<0.001$ & $1.6(1.29-2.00)$ & $<0.001$ \\
\hline \multicolumn{7}{|l|}{ Drug Resistance } \\
\hline RR-/MDR-TB & 405 & $218(53.83)$ & 7.29 (3.31 - 16.03) & $<0.001$ & $9.32(7.28-1.93)$ & $<0.001$ \\
\hline \multicolumn{7}{|l|}{ History of Previous TB Treatment } \\
\hline Treatment after Lost to Follow-up & 366 & $88(24.04)$ & $1.79(1.27-2.52)$ & 0.001 & $1.84(1.37-2.47)$ & $<0.001$ \\
\hline Previous Treatment Outcome Unknown & 265 & $61(23.02)$ & $1.38(0.93-2.05)$ & 0.111 & $1.42(1.00-2.01)$ & 0.048 \\
\hline
\end{tabular}

those with negative results and those who used other diagnostic tests $(\mathrm{OR}=2.85$; 95\%CI 2.36-3.44). Patients whose Xpert MTB/RIF test detected both MTB and Rifampicin resistance were more than 11 times more likely to have unsuccessful treatment outcome $(\mathrm{OR}=11.29$; 95\%CI 8.75-14.56). Patients with RR-/MDR-TB were also 11.29 times more likely to have an unsuccessful treatment outcome than those who were drug susceptible (95\%CI 8.99-14.18). Furthermore, patients who were categorized as relapse cases $(\mathrm{OR}=1.61 ; 95 \% \mathrm{CI} 1.28-2.04)$, treatment after failure cases $(\mathrm{OR}=5.36$; 95\%CI 3.29-8.73), treatment after lost to follow-up cases $(\mathrm{OR}=3.17 ; 95 \% \mathrm{CI}$ 2.34-4.27), and cases with previously unknown treatment outcome $(\mathrm{OR}=2.99$; 95\%CI 2.13-4.19) had higher odds of having unsuccessful treatment outcome.
In the multiple logistic regression analysis, it was found that patients who were between 25 to 34 years old $(\mathrm{aOR}=0.73$; 95\%CI $0.54-0.99)$ and 35 to 44 years old $(\mathrm{aOR}=0.75$; 95\%CI $0.56-0.99)$ were less likely to have unsuccessful treatment outcome. Males were found to be $30 \%$ more likely of having an unsuccessful outcome $(\mathrm{aOR}=1.30 ; 95 \% \mathrm{CI} 1.03-1.64)$ than females. The odds of having unsuccessful treatment outcome decreased by $34 \%$ for patients who were craft and related trades workers (aOR=0.66; 95\%CI 0.46-0.94). Those who are living in a 1 st class municipality $(\mathrm{aOR}=0.75 ; 95 \% \mathrm{CI} \quad 0.57-0.98)$, 4 th class city $(\mathrm{aOR}=0.46 ; 95 \% \mathrm{CI} 0.26-0.82)$, or 4 th class municipality $\quad(\mathrm{aOR}=0.59$; 95\%CI $0.38-0.93$ ) were less likely to have unsuccessful treatment outcome. Having a positive sputum smear result increased the odds of having 
unsuccessful treatment outcome by $60 \%(\mathrm{aOR}=1.60 ; 95 \% \mathrm{CI}$ 1.29-2.00). Patients with RR-/MDR-TB were 9.32 times more likely to have an unsuccessful treatment outcome (95\%CI 7.28-11.93). Moreover, treatment after lost to follow-up cases $(\mathrm{aOR}=1.84 ; 95 \% \mathrm{CI} 1.37-2.47)$ and cases with previously unknown treatment outcome $(\mathrm{aOR}=1.42$; 95\% 1.00-2.01) had higher odds of having an unsuccessful treatment outcome. Among all the variables included in the model, the study revealed that there was no sufficient evidence to conclude that Xpert MTB/RIF result was associated with $\mathrm{TB}$ treatment outcome.

\section{DISCUSSION}

Multiple regression analysis showed that males, patients with RR/MDR-TB, those with a positive sputum smear result, those with a history of having lost to follow up, or unknown previous treatment outcome before retreatment were more likely of having unsuccessful treatment outcome. Among the 338,376 PTB patients included in the study, $8.73 \%$ were found to have an unsuccessful treatment outcome. This means that the NTP successfully reached the 90\% target for TSR for 2016 despite having TSRs of three regions (i.e. Region VIII, NCR, and CAR) falling short from the target. According to the NTP, this high TSR could be related to the countrywide implementation of TB treatment programs, decentralization of treatment services, the participation of community volunteers, and other strategies that improved case holding. The decentralization allowed the patients to have access to treatment and be followed-up regularly within their communities. ${ }^{4}$

\section{Sociodemographic Factors}

Most studies showed that there was an increasing likelihood of having an unsuccessful treatment outcome as one ages..$^{8-13}$ According to these studies, the reported trend may be attributed to the increased risk of having comorbidities, immunosuppression, and unfavorable drug reactions, as well as physical deterioration. ${ }^{8,10,11}$ This is somehow seen in the NTPS 2016 where younger participants of the survey did not take any action when presented with TB symptoms because they were concerned of being absent at work or school with the 15 to 24 -yearold age group having the highest proportion for this occurrence (45.9\%). This was attributed to the superior strategies and better coping mechanisms of older patients. ${ }^{14}$ It should be noted that these results, as also shown by their confidence intervals, were of borderline significance.

The study presented the same result compared to the trend in other researches where males were more likely to have an unsuccessful treatment outcome compared to females. ${ }^{8,15}$ In the NTPS 2016, more females (23.3\%) were found to consult with a healthcare worker as compared to males (15.9\%), which may indicate better health-seeking behaviors of females than males, that is also seen in a cross- sectional survey of presumptive TB patients in Zambia. ${ }^{16}$ In addition, smoking and alcohol consumption might have contributed to the association established as they act as possible confounders since studies found associations between the vices and treatment outcome..$^{17,18}$

The multiple logistic regression analysis showed that occupation was associated with treatment outcome; specifically, people whose occupations were classified under craft and related trades work were found to be less likely of having an unsuccessful treatment outcome. Occupation, as well as education, can be used to assess the social status of an individual, which can affect a person's risk for health problems as well as the quality of health care service. ${ }^{18}$ Lower income, along with poor education levels, can be associated with poorer health behavior since their living conditions, as well as practices, may promote the propagation and progression of the disease. Studies associating treatment outcome with social status have found similar findings, where those who were unemployed were more likely to die or be lost to follow-up. ${ }^{8,19,20}$ Moreover, low educational level was found to be associated with poor patient adherence to PTB treatment in a study conducted by Choi in $2016 .{ }^{21}$

The study found that those who are living in a 1 st class municipality, 4th class city, or 4th class municipality were less likely to have an unsuccessful treatment outcome. According to the World Health Organization, poor living conditions worsen infectious diseases. The high rate of urban migration leading to overpopulation and overcrowding, which is a significant factor for disease transmission. ${ }^{22}$ This situation may also be seen in the National Capital Region, a congested and dense region where $48.33 \%$ of those under the 1 st income class city resided. The NTPS 2016 found that among those who were treated in 2011 onwards, more patients in rural areas received anti-TB drugs compared to those in urban areas, despite a high proportion of rural dwellers not taking any action in response to TB symptoms $(43.2 \%){ }^{3}$ Low utilization of health services may also be attributed to cities, even though they are characterized to have a multitude of health and social services when compared to rural areas. ${ }^{22}$ According to Cetrangolo et al., lack of information on benefits as well as the perception of poor quality of healthcare services also serves as barriers towards the provision of health services. ${ }^{23}$ This may be seen from the results in the NTPS 2016, where a higher proportion of urban dwellers admitted themselves to self-medication (44.6\%) which may be attributed to the urban dwellers' perception that their symptoms were insignificant, in addition to the fact that they were not at ease with or did not trust their healthcare providers.

\section{TB-Related Factors}

The results revealed that patients who tested positive in the DSSM test were $60 \%$ more likely to have an unsuccessful treatment outcome compared to those who had a negative result, as seen in other studies. ${ }^{8,13,24,25}$ This association 
might be due to the extensive disease severity at diagnosis compounded by other health factors and vices, advanced disease progression, and mixed infection of different MTB strains. ${ }^{26,27}$ It may also be explained by the poor response to treatment due to the presence of drug resistance, delays in treatment initiation and patient presentation to health facilities, and poor patient monitoring throughout the course of treatment. ${ }^{27}$

Similar to the obtained results, a study by Aibana et al. did not find any significant association between GeneXpert results and poor treatment outcome of people with MDR-TB, as compared to those who did not perform the test $(\mathrm{aOR}=1.31 ; 95 \% \mathrm{CI} \quad 0.62-2.73){ }^{28}$ However, a follow-up of a clinical trial has shown that TB-related mortality among patients is lower among those diagnosed via GeneXpert as compared to those who were diagnosed via sputum smear microscopy ${ }^{29}$; nonetheless, unfavorable outcomes in both groups were contributed by loss to followup. Furthermore, patients with indeterminate Rifampicinresistance may be due to a mixed infection of drugsusceptible and drug-resistant MTB strains. Although mixed infections are associated with poor treatment outcome, this cannot be concluded in the data analyzed for logistic regression as those included were found to have successful treatment outcome. ${ }^{30}$

According to Sengul et al., patients with Rifampicin resistance (cOR=1.4; 95\% CI 1.1-1.9), and multidrug resistance $(\mathrm{cOR}=1.6 ; 95 \% \mathrm{CI}$ 1.1-2.2) were more likely to have unsuccessful treatment outcome. ${ }^{11}$ Similarly, in this study, an association between drug resistance and unsuccessful treatment outcome was also observed, where RR-/MDR-TB patients were 9.32 times (95\% CI 8.7113.62) more likely of having an unsuccessful outcome. Given that RR-/MDR-TB patients are treated for about 18 months or longer, the length of regimen and combination of drugs may cause intolerable adverse reactions to patients and may likely affect their treatment adherence. ${ }^{11}$

In this study, it was revealed that patients who had their treatment after being lost to follow-up were almost two times more likely of having an unsuccessful treatment outcome. The study also showed that patients whose previous treatment outcome was unknown were also more likely to have an unsuccessful treatment outcome. These findings were consistent with other studies that have shown the significant association of retreatment cases with unsuccessful treatment outcome. ${ }^{8-11,31}$ These may be explained by the findings of the study by da Silva Garrido et al. which shows that previous defaulting (i.e., treatment after lost to follow-up) was a risk factor $(\mathrm{aOR}=3.20$; $95 \% \mathrm{CI}$ 2.25-4.57) for re-defaulting (i.e., an unsuccessful treatment outcome of being lost to follow-up). ${ }^{11}$ The NTPS 2016 suggested that patients are likely to default from treatment because of the side effects of drugs, a far distance of the health center, weakness of the patient to go to the health center, cost of drugs, and the stock-out of drugs. ${ }^{3}$

\section{Limitations of the Study}

The analytic cross-sectional study design has an inherent limitation of difficulty in establishing a temporal relationship between exposure and outcome. Moreover, misclassification bias may have been present. Since the data used were primarily collected for clinical and administrative purposes, data quality in terms of its completeness and accuracy could not be fully ensured for this study. On the part of the researchers, further misclassification bias was minimized by ensuring accurate data re-coding and editing.

The study results may only be reflective of the registered population since some characteristics may be different to those not enrolled in these facilities. It is also possible that the characteristics of the patients included in the study significantly differ between those with complete data since some variables and categories were no longer included in the regression analysis. STATA automatically drops records with missing data and performs regression analysis only on entries (i.e., patient records) with complete data on all variables for analysis. Hence, the possibility of selection bias cannot be ruled out. It must be noted that although treatment outcome may be dependent on comorbidities, it was not included in the logistic regression model; hence, its possible confounding effect on other factors was not taken into account. The study used the method of restriction, inclusion and exclusion criteria, and multiple logistic regression analysis in controlling the effects of other variables such as confounding.

\section{CONCLUSION}

The study found that male patients, those with rifampicin or multidrug resistance (RR/MDR-TB), a positive sputum smear result, a history of having lost to follow up, or unknown previous treatment outcome before retreatment were more likely of having unsuccessful treatment outcome. These agreed with the results of other studies conducted in several settings.

On the contrary, age groups 25 to 34 years old and 35 to 44 years old, craft and related trades workers, and residing in 1st income class municipality, 4th income class city, and 4th income class municipality were found to be less likely of having unsuccessful treatment outcome. In addition, it may be worthwhile to note that TB-related factors may be more associated with unsuccessful treatment outcome compared to socio-demographic factors since the confidence intervals of the latter group were of borderline significance.

\section{Recommendations}

For policymakers and TB program managers, TB patients with the prognosticating factors for unsuccessful treatment outcome (i.e., as identified by this study) may require better attention in terms of treatment monitoring. TB DOTS facilities are recommended to further improve their compliance with the protocols of the NTP with regard 
to collecting patient information to ensure completeness of data for both surveillance and research purposes. Lastly, the study may be useful in resource allocation, developing patient-centered care, treatment models, interventions, and projects addressing those who have predictors of unsuccessful treatment outcome that complements the current TB control program.

For future researches, collection of primary data on other variables that were not further analyzed in this study and may not be routinely collected by the NTP may be essential. Other study designs such as case-control and cohort studies must be conducted in the hopes of establishing temporal sequence between exposure and the outcome and provide stronger evidence of causality. Also, future studies may not limit their studies to a one-year time span and check if the assumption of the study is true. Researchers may use higher statistical methods to look into the association between the said variables and each of the five treatment outcomes. Areas on which future studies would be beneficial are: (1) the association of income classifications of residence with tuberculosis treatment outcome and (2) the interactions of all the variables which were found to be associated with tuberculosis treatment outcome to further explore the underlying mechanisms explaining their association with the outcome.

\section{Acknowledgments}

The researchers would like to express their utmost gratitude to Dr. Mario S. Baquilod, Officer in Charge of the Disease Prevention and Control Bureau, Dr. Anna Marie Celina G. Garfin, NTP Manager, Ms. Donna Mae G. Gaviola, Project Coordinator for Data and Information, and the rest of the NTP-DOH team; Dr. Jacinto Blas V. Mantaring III, Chairperson of the University of the Philippines Manila - Research Ethics Board (UPMREB), and Professor Edlyn Jimenez, UPMREB Coordinator; Dr. Ma. Susan T. Yanga-Mabunga, Committee Chairperson, and the respected members of the PH 197/199 Committee; and the faculty and staff of the Department of Epidemiology and Biostatistics of the College of Public Health.

\section{Statement of Authorship}

All authors approved the final version submitted.

\section{Author Disclosure}

The authors declare no conflict of interest.

\section{Funding Source}

None.

\section{REFERENCES}

1. World Health Organization. Global tuberculosis report 2016 [Internet]. 2016 [cited 2017 Oct]. Available from http://apps.who.int/ medicinedocs/documents/s23098en/s23098en.pdf
2. World Health Organization. Global tuberculosis report 2017 [Internet]. 2017 [cited 2017 Oct]. Available from http://apps.who.int/ medicinedocs/documents/s23360en/s23360en.pdf

3. Department of Health. National Tuberculosis Prevalence Survey 2016 [Internet]. 2016 [cited 2017 Nov]. Available from http://ntps. healthresearch.ph/content/2016- ntps-results

4. National Tuberculosis Program. Framework of the PhilSTEP and Targets [Internet]. 2017 [cited 2017 Oct]. Available from http:// www.ntp.doh.gov.ph/downloads/ntp_data/ntp_vmg_and_org_and_ tb_burden.pdf

5. Shimazaki T, Marte SD, Saludar NR, Dimaano EM, Salva EP, Ariyoshi K, et al. Risk factors for death among hospitalised tuberculosis patients in poor urban areas in Manila, The Philippines. Int J Tuberc Lung Dis. 2013;17(11):1420-6.

6. Tupasi TE, Garfin AG, Kurbatova EV, Mangan JM, Orillaza-Chi R, Naval LC, et al. Factors associated with loss to follow-up during treatment for multidrug-resistant tuberculosis, the Philippines, 20122014. Emerg Infect Dis. 2016; 22(3):491-502.

7. National Tuberculosis Control Program. National Tuberculosis Control Program Manual of Procedures: 5th edition [Internet]. 2014 [cited 2017 Oct]. Available from http://www.ntp.doh.gov.ph/ downloads/NTP_MOP_5th_Edition.pdf

8. Gadoev J, Asadov D, Tillashaykhov M, Tayler-Smith K, Isaakidis P, Dadu A, et al. Factors associated with unfavorable treatment outcomes in new and previously treated TB patients in Uzbekistan: a five year countrywide study. PloS One. 2015; 10(6):e0128907.

9. Gebrezgabiher G, Romha G, Ejeta E, Asebe G, Zemene E, Ameni G. Treatment outcome of tuberculosis patients under directly observed treatment short course and factors affecting outcome in Southern Ethiopia: a five-year retrospective study. PLoS ONE. 2016; 11(2)1:e0150560.

10. Berhe G, Enquselassie F, Aseffa A. Treatment outcome of smearpositive pulmonary tuberculosis patients in Tigray Region, Northern Ethiopia. BMC Public Health. 2012; 12:537.

11. Sengul A, Akturk UA, Aydemir Y, Kaya N, Kocak ND, Tasolar FT. Factors affecting successful treatment outcomes in pulmonary tuberculosis: a single-center experience in Turkey, 2005-2011. J Infect Dev Ctries. 2015; 9(8):821-8.

12. Vasankari T, Holmström P, Ollgren J, Liippo K, Kokki M, Ruutu P. Risk factors for poor tuberculosis treatment outcome in Finland: a cohort study. BMC Public Health. 2007; 7:291.

13. Jackson C, Stagg HR, Doshi A, Pan D, Sinha A, Batra R, et al. Tuberculosis treatment outcomes among disadvantaged patients in India. Public Health Action. 2017; 7(2):134-40.

14. Kigozi G, Heunis C, Chikobvu P, Botha S, van Rensburg D. Factors influencing treatment default among tuberculosis patients in a high burden province of South Africa. Int J Infect Dis. 2017; 54:95-102.

15. Atif M, Sulaiman SA, Shafie AA, Ali I, Asif M, Babar ZU. Treatment outcome of new smear positive pulmonary tuberculosis patients in Penang, Malaysia. BMC Infect Dis. 2014; 14:399.

16. Silva MR, Pereira JC, Costa RR, Dias JA, Guimarães MDC, Leite ICG. Drug addiction and alcoholism as predictors for tuberculosis treatment default in Brazil: a prospective cohort study. Epidemiol Infect. 2017; 145(16):3516-24.

17. Trajman A, Durovni B, Saraceni V, Menezes A, Cordeiro-Santos $\mathrm{M}$, Cobelens $\mathrm{F}$, et al. Impact on patients' treatment outcomes of XpertMTB/RIF implementation for the diagnosis of tuberculosis: follow-up of a stepped-wedge randomized clinical trial. PLoS One. 2015; 10(4):e0123252.

18. Hollingshead AB. Two factor index of social position. New Haven: Yale University Press; 1957.

19. Li T, Zhang H, Wang LX, Pang Y, DU X. Description and factors affecting the referral of presumptive tuberculosis patients in China. Biomed Environ Sci. 2017; 30(6):444-9.

20. de Seixas Maciel EM, de Souza Amancio J, de Castro DB, Braga JU. Social determinants of pulmonary tuberculosis treatment non-adherence in Rio de Janeiro, Brazil. PloS One. 2018; 13(1):e0190578. 
21. Choi H, Chung H, Muntaner C, Lee M, Kim Y, Barry CE, et al. The impact of social conditions on patient adherence to pulmonary tuberculosis treatment. Int J Tuberc Lung Dis. 2016; 20(7):948-54.

22. World Health Organization. Why urban health matters [Internet]. 2010 [cited 2017 Oct] Available from http://www.who.int/worldhealth- day/2010/media/whd2010background.pdf

23. Cetrángolo O, Mesa-Lago C, Lazaro G, Carisma SK. Health Care in the Philippines: Challenges and Ways Forward. Friedrich-EbertStiftung-Philippine Office; 2013.

24. Tesfahuneygn G, Medhin G, Legesse M. Adherence to Antituberculosis treatment and treatment outcomes among tuberculosis patients in Alamata District, northeast Ethiopia. BMC Res Notes. 2015; 8:503

25. Reis-Santos B, Gomes T, Locatelli R, de Oliveira ER, Sanchez MN, Horta BL, et al. Treatment outcomes in tuberculosis patients with diabetes: a polytomous analysis using Brazilian surveillance system. PLoS One. 2014; 9(7):e100082.

26. Kilicaslan Z, Ozturk F, Sarimurat N, Cuhadaroglu C, Caglar E, Erem A. Microscopic examination and treatment outcomes of new pulmonary tuberculosis cases in Istanbul dispensaries between 1998 and 2000. Int J Tuberc Lung Dis. 2003; 7(11):1059-3.
27. Cox H, Kebede Y, Allamuratova S, Ismailov G, Davletmuratova $\mathrm{Z}$, Byrnes G, et al. Tuberculosis recurrence and mortality after successful treatment: impact of drug resistance. PLoS Med. 2006; 3(10):e384.

28. Aibana O, Bachmaha M, Krasiuk V, Rybak N, Flanigan TP, Petrenko $\mathrm{V}$, et al. Risk factors for poor multidrug-resistant tuberculosis treatment outcomes in Kyiv Oblast, Ukraine. BMC Infect Dis. 2017; 17(1):129.

29. Kaur R, Kachroo K, Sharma JK, Vatturi SM, Dang A. Diagnostic accuracy of Xpert test in tuberculosis detection: a systematic review and meta-analysis. J Glob Infect Dis. 2016; 8(1):32-40.

30. Zetola NM, Shin SS, Tumedi KA, Moeti K, Ncube R, Nicol M, et al. Mixed mycobacterium tuberculosis complex infections and falsenegative results for rifampicin resistance by GeneXpert MTB/ RIF are associated with poor clinical outcomes. J Clin Microbiol. 2014; 52(7):2422-9.

31. Cherkaoui I, Sabouni R, Ghali I, Kizub D, Billioux AC, Bennani $\mathrm{K}$, et al. Treatment default amongst patients with tuberculosis in urban Morocco: predicting and explaining default and post-default sputum smear and drug susceptibility results. PloS One. 2014 9(4):e93574. 